\title{
Investigation of the Determinants of the Survival of Neisseria gonorrhoeae within Human Polymorphonuclear Phagocytes
}

\author{
By N. J. PARSONS, A. A. A. KWAASI, J. A. TURNER, \\ D. R. VEALE, V. Y. PERERA, C. W. PENN AND H. SMITH* \\ Department of Microbiology, University of Birmingham, PO Box 363, \\ Birmingham B15 2TT, U.K.
}

(Received 26 February 1981)

\begin{abstract}
In studies aimed at identifying the determinants responsible for the ability of gonococci to survive and grow within human phagocytes, the reduction of intracellular survival of phagocyte-resistant gonococci by prior treatment of the bacteria with homologous antiserum provided two indirect means of testing for possible determinants. First, surface washes of the resistant gonococci and fractions of these extracts were examined for ability to neutralize the above effect of antisera. Second, antisera raised to purified surface components of the resistant organisms were examined for ability to promote intracellular killing. A combination of these methods indicated that the aggressins were not pili but components of the outer membrane.

A surface wash of a phagocyte-resistant, pilated strain, BS4 (agar), neutralized the activity of homologous antisera before and after centrifuging at $20000 \mathrm{~g}$, but pili separated from the supernatant did not. A corresponding supernatant from the surface wash of a phagocytesusceptible strain, BSSH, had little neutralizing ability. Antisera to pili failed to reduce intracellular survival of resistant gonococci, whereas antisera against outer membrane vesicles did so. Finally, the neutralizing activity of the surface wash supernatant was removed by centrifugation after treatment with wheat germ agglutinin, which precipitates outer membrane vesicles.
\end{abstract}

\section{INTRODUCTION}

Intracellular survival and growth appears to be a significant feature in the pathogenicity of gonococci. Phagocytosis tests in vitro with gonococci grown in vitro and in vivo and phagocytes from human peripheral blood or urethral exudates (Witt et al., 1976 $a$, $b$; Veale et al., 1976, 1979; Casey et al., 1979, 1980) have confirmed indications from light and electron microscopy of urethral exudates (Ward et al., 1972; Farzadegan \& Roth, 1975; Novotny et al., 1975; Ovchinnikov \& Delektorskij, 1977) that some gonococci can survive and grow within human phagocytes. The gonococci that were resistant to killing by phagocytes produced colonies that showed a characteristic double highlight (DH) morphology in a system of transmitted and reflected light (Penn et al., 1977). These gonococci predominated in populations that were grown in vivo in subcutaneous chambers in guinea-pigs and examined either directly or after minimal subculture on AG agar (Penn et al., 1977). They could, however, be selected in vitro from a laboratory strain (BS) which also contained many organisms sensitive to phagocyte killing that formed colonies with a single highlight (SH) morphology and were less pilated than DH organisms (Penn et al., 1977). Thus, there was an apparent association of pilation with resistance to killing by phagocytes (Penn et al., 1977).

In seeking to identify the determinants of resistance to intracellular killing, the first requirement was to develop a test for them. The simplest test, the direct promotion of resistance to the intracellular killing of susceptible SH organisms by the addition of extracts of 
resistant organisms. suffered from the difficulty that the determinant might never enter the relevant phagosome to exert its effect unless it became attached to the surface of the susceptible organism. Indirect tests became available, however, when Veale et al. (1978) showed that the resistance of DH organisms to phagocyte killing was neutralized by an antiserum against intact homologous organisms, but not by antiserum which had been adsorbed either with whole organisms or extracts of them. Thus, it appeared that determinants on the surface of resistant organisms could be neutralized by antibody. Two means were now available to test indirectly for the presence of such determinants. Firstly, fractions of surface extracts could be examined for their ability to prevent the reduction in resistance to phagocyte killing produced by antisera to whole organisms. Secondly, antisera raised to purified surface components of the resistant organisms could be examined for their ability to promote intracellular killing. Both means have been used in a preliminary examination of the determinants of intracellular survival.

In previous work (Veale et al., 1978) a DH strain (BSDH) selected in vitro from the laboratory BS strain (Penn et al., 1977) was used both as the resistant organism in phagocytosis tests and for preparing extracts that adsorbed from homologous antiserum the antibodies that promoted intracellular killing (Veale et al., 1978). However, ultrasonic treatment was needed to prepare active extracts from these BSDH organisms; surface washes prepared by vortex mixing with glass beads, which contain fewer intracellular components, were seldom active (Veale et al., 1978). Later work showed that, unlike sonication, such washing also failed to remove from BSDH organisms surface antigens that were found in surface washes of strains BS3 (agar) and BS4 (agar) isolated by passing strain BS through guinea-pig subcutaneous chambers three or four times and then growing once on AG agar (Penn et al., 1978: Parsons et al., 1979, 1980). These strains, like strain BSDH, were DH, pilated and resistant to killing by phagocytes (Penn et al., 1977). A surface wash of BS4 (agar) neutralized promotion of intracellular killing of BS4 (agar) by homologous antiserum (or that against BSDH). Since sonication was not needed to liberate neutralizing antigens, BS4 (agar) was chosen as the test organism for future work.

\section{METHODS}

Organism. Neisseria gonorrhoeae strains BS4 (agar), BS4R and BSSH, (SH organisms selected from strain BS) were described by Penn et al. $(1976,1978)$ and Parsons et al. (1979). They were stored, cultured and counted as described previously (Veale et al.. 1975; Penn et al., 1976).

Surface washes of strains BS4 (agar) and BSSH. Organisms were grown on AG agar (Penn et al., 1976) for 22 $h$ at $37^{\circ} \mathrm{C}$ and suspended in phosphate-buffered saline (PBS, pH 7.2; Penn et al., 1976) at a concentration of $10^{11}$ gonococci $\mathrm{ml}^{-1}$. After vortex mixing (Whirlimixer, Fisons Scientific Apparatus) with glass beads (3 mm diam., 5-8 per $\mathrm{ml}$ suspension) for $6 \mathrm{~min}$, the suspension was centrifuged $(2000 \mathrm{~g}, 15 \mathrm{~min}$, room temperature) and the supernatant removed. Total and viable counts showed that this washing procedure did not cause appreciable lysis or killing of the gonococci. Freshly prepared surface washes were used in each experiment.

Some surface washes from BS4 (agar) were separated immediately into two fractions by centrifuging $(20000 \mathrm{~g}$, $30 \mathrm{~min}, 4^{\circ} \mathrm{C}$ ): the supernatants were tested directly and the deposits after suspension in PBS to the original volume of the surface wash. Some supernatants were also examined after treatment with wheat germ agglutinin (WGA; Sigma) which precipitated outer membrane vesicles (Perera et al., 1980). After mixing with an equal volume of a solution of WGA (1 mg ml-1; $\mathrm{pH} \mathrm{7.2)} \mathrm{in} \mathrm{PBS} \mathrm{in} \mathrm{Dreyer} \mathrm{tubes} \mathrm{and} \mathrm{standing} \mathrm{for} 30$ min at $0^{\circ} \mathrm{C}$ the flocculent precipitate was removed by centrifugation $(1500 \mathrm{~g}, 15 \mathrm{~min}$, room temperature) and the supernatant tested.

Preparation of pili from strain BS4 (agar). The method of Robertson et al. (1977) was used. Sheared pili present in the surface washes (see above) were disaggregated by addition of sucrose to a final concentration of $1 \mathrm{M}$. After standing for $1 \mathrm{~h}$ at $0^{\circ} \mathrm{C}$, whole organisms and outer membranes were removed by centrifugation $(10000 \mathrm{~g}$, $30 \mathrm{~min} .4^{\circ} \mathrm{C}$; then $15000 \mathrm{~g}, 1 \mathrm{~h}, 4^{\circ} \mathrm{C}$ ). Pili in the supernatant were aggregated by addition of $\mathrm{NaCl}$ to $1 \mathrm{M}$ concentration. After standing for $1 \mathrm{~h}$ at $0^{\circ} \mathrm{C}$, the pili were collected by centrifugation $\left(100000 \mathrm{~g}, 4 \mathrm{~h}, 4^{\circ} \mathrm{C}\right)$. The pellet was washed three times with PBS $(5 \mathrm{ml})$ and resuspended in PBS in $1 / 25$ of the original volume of the surface wash which related to $1 \times 10^{11}$ gonococci $\mathrm{ml}^{-1}$. Pili examined by electron microscopy showed no contamination (Fig. 1); in two-dimensional immunoelectrophoresis with antisera against BS4 (agar) the 


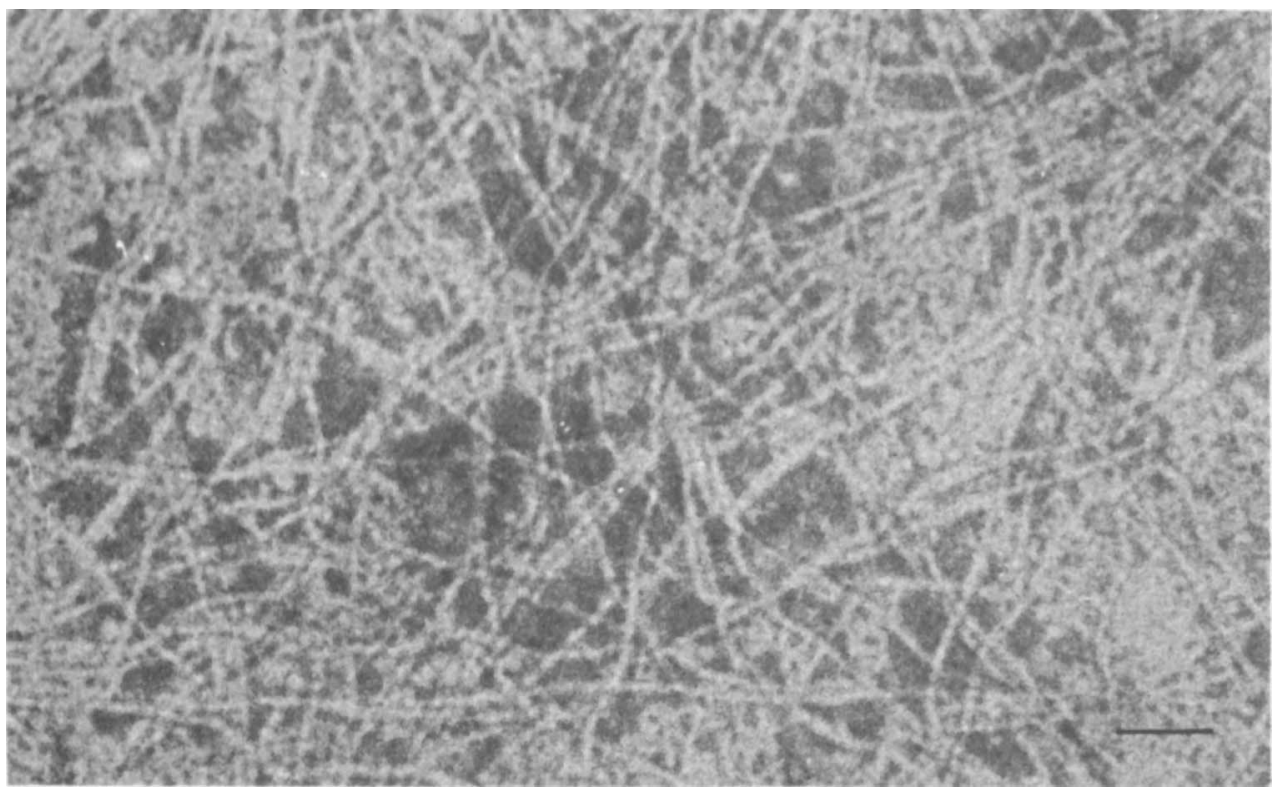

Fig. 1. Electron micrograph of purified pili. The bar marker represents $0.2 \mu \mathrm{m}$.

concentrated suspensions of pili showed a strong $a$ line (Parsons et al., 1979) but small amounts of other surface antigens of BS4 (agar) were present.

Antiserum against whole organisms. Rabbit antisera to BSDH and BS4 (agar) were raised by multiple intravenous injections of live organisms in Trypticase Soy Broth (TSB; Baltimore Biological Laboratories) as described by Veale et al. (1978) for production of hyperimmune antisera. Antiserum to BSDH was used first in the phagocytosis tests but was superseded later by antiserum to BS4 (agar) without any change in the pattern of results. To obtain adsorbed antisera, equal volumes of surface washes, their $20000 \mathrm{~g}$ supernatants and suspended deposits or suspensions of pili were mixed with antiserum and allowed to stand overnight at $4{ }^{\circ} \mathrm{C}$. For adsorption with WGA-treated supernatants from surface washes (see above), antiserum was mixed with two volumes of the centrifuged mixture.

Antiserum against pili. Antigen $a$, the type-specific antigen present in surface washes of BS3 (agar) and BS4 (agar) (Penn et al., 1978; Parsons et al., 1979), is composed of pili (Penn et al., 1980). Antisera were raised in two rabbits against this pilus antigen by subcutaneous injection of antibody complexes excised from two-dimensional immunoelectrophoresis gels as described by Parsons et al. (1979) for immunization of guinea-pigs. The rabbit antisera (R1 and R2) formed strong lines corresponding to the $a$ antigen in two-dimensional immunoelectrophoresis with surface washes of BS4 (agar), and reacted with pili on this strain in immune electron microscopy (Penn et al., 1980). However, they contained traces of antibodies to other antigens as shown in two-dimensional immunoelectrophoresis against surface washes of BS4 (agar). These small quantities of other antibodies were removed for some experiments by adsorption with strain BS4R as described by Parsons et al. (1979).

Antiserum against outer membrane vesicles. Outer membrane vesicles of BS4 (agar) were precipitated by WGA in cross-affinity electrophoresis and the excised precipitation lines were used to raise antisera in rabbits (Perera $e t$ al., 1980). These antisera (R3 and R4) formed, with surface washes of BS4 (agar) in two-dimensional immunoelectrophoresis, a strong line corresponding with the $c$ line described by Parsons et al. (1979) and only traces of other lines. The antisera also reacted with outer membrane vesicles from BS4 (agar) in immune electron microscopy (Perera et al., 1980).

Two-dimensional immunoelectrophoresis. This was performed as described by Penn et al. (1978).

Treatment of gonococci with antisera before phagocytosis tests. Gonococci [BS4 (agar) in most tests; BSSH in a few tests; $\left.2 \times 10^{7} \mathrm{ml}^{-1}\right]$ were incubated $\left(1 \mathrm{~h}, 37^{\circ} \mathrm{C}\right)$ in Parker medium 199 containing $10 \%(\mathrm{v} / \mathrm{v})$ heated $\left(56^{\circ} \mathrm{C}\right.$, $30 \mathrm{~min}$ ) human serum (HHS) obtained from defibrinated blood and $1 \%(\mathrm{v} / \mathrm{v})$ rabbit antiserum or the corresponding concentration of adsorbed antiserum (see above). Antisera were omitted from control samples. The medium was then removed by centrifugation $(2000 \mathrm{~g}, 3 \mathrm{~min}$, room temperature) and after washing three times with 
fresh medium $(1 \mathrm{ml})$ without antisera, the gonococci were suspended at a concentration of $2 \times 10^{6} \mathrm{ml}^{-1}$ in Parker medium 199 containing HHS ( $10 \%, \mathrm{v} / \mathrm{v})$, for mixing with the phagocytes in the Leighton tubes.

Test for resistance of gonococci to killing by human phagocytes. The test was the same as that described by Penn et al. (1977) and Veale et al. (1978) with modifications for determinations of total phagocytes present and the viable count of gonococci in phagocyte deposits.

After treatment with antisera as described above, the treated and control suspensions of gonococci $(0.5 \mathrm{ml} ; 2 \times$ $10^{6} \mathrm{ml}^{-1} ;>60 \%$ viable) were mixed in Leighton tubes with an equal volume of suspensions of human phagocytes $\left(2 \times 10^{6} \mathrm{ml}^{-1}\right.$; about $80 \%$ PMN phagocytes) prepared from fresh human peripheral blood as described by Witt $e t$ al. $(1976 \mathrm{~b})$, and suspended in Parker medium 199 with HHS $(10 \%, \mathrm{v} / \mathrm{v})$. After incubation for $1 \mathrm{~h}$ at $37^{\circ} \mathrm{C}$, the medium was discarded and the infected phagocyte deposit washed three times with PBS containing bovine serum albumin (BSA: $0.1 \%, w / v)$. The following determinations were made on the infected phagocytes: (1) the number of gonococci per phagocyte - phagocytic index - seen microscopically on stained films on coverslips placed on the flat surface of the Leighton tubes (Veale et al., 1975: Witt et al., 1976a,b); (2) the total number of phagocytes in the infected deposit by a rapid assay for DNA (see below); and (3) the number of viable gonococci, determined by plating a portion of the material used for DNA assay (see below), and not as previously (Witt et al., 1976a,b). The viable counts were corrected for settled non-cell-associated gonococci by deducting the low viable counts $(<10 \%$ of those in the tubes containing phagocytes) found in control tubes without phagocytes. The results were expressed as the percentage of the total cell-associated gonococci (the product of the phagocytic index and the total number of phagocytes) that were viable. Previous work has shown that at this stage in the phagocytosis test almost all the cell-associated gonococci are intracellular (Witt et al., 1976a, b; Veale et al., 1978). Similar results were obtained after deposits of infected phagocytes were incubated for $2 \mathrm{~h}$ in tissue culture medium containing spectinomycin $\left(20 \mu \mathrm{g} \mathrm{ml}^{-1}\right)$ and fresh human serum $(10 \%, \mathrm{v} / \mathrm{v})$ which killed all extracellular gonococci (Casey et al., 1979). This longer test was not suitable for the routine examination of surface wash fractions.

The total number of phagocytes in the deposits of Leighton tubes was determined from their content of DNA using a modification of the method of Bonting \& Jones (1957). Washed deposits of infected cells were suspended in $75 \mu ! 0.1 \%(\mathrm{w} / \mathrm{v})$ BSA in PBS by scraping with a rubber-tipped glass rod. Suspensions from three replicate tubes were pooled and $20 \mu \mathrm{l}$ was removed for an immediate viable count of gonococci. The remaining pooled phagocyte suspension was treated with $5 \mathrm{M}-\mathrm{NaOH}(50 \mu \mathrm{l})$ for $1 \mathrm{~h}$ at $37^{\circ} \mathrm{C}$ and then with indole reagent (indole. $0.02 \%, w / v$ in $5 \mathrm{M}-\mathrm{HCl}: 250 \mu \mathrm{l})$ for $10 \mathrm{~min}$ at $100{ }^{\circ} \mathrm{C}$. Cooled samples were extracted with chloroform $(1 \mathrm{ml})$ by vortex mixing $(30 \mathrm{~s})$ and the absorbance $(490 \mathrm{~nm}$ : in an SP1800 Spectrophotometer, Pye Unicam) of the aqueous phase obtained by centrifugation $(3000 \mathrm{~g}, 10 \mathrm{~min}$, room temperature) was read against a blank of $0.1 \%(\mathrm{w} / \mathrm{v})$ BSA in PBS after reaction with the indole reagent. The number of phagocytes on the surface of the Leighton tube was obtained from a standard curve relating $A_{490}$ to numbers of phagocytes obtained from 12 different donors. In individual phagocytosis tests, the $A_{490}$ value obtained from $2.4 \times 10^{5}$ phagocytes taken from the original suspension (i.e. equivalent to $8 \times 10^{4}$ in each of the three tubes) was checked for fit with the curve. In most tests the $A_{490}$ values of experimental and control samples fell in the linear range of the curve and indicated $4 \times 10^{4}-2 \times 10^{5}$ phagocytes in the deposits in each tube.

These indirect phagocytosis tests for the determinants of intracellular survival gave variable results and only by repeating them on many batches of material were unequivocal results achieved. The results presented are from representative experiments: the variable viability of gonococci in phagocyte deposits from different donors on different days precluded the presentation of mean values and standard errors.

\section{RESULTS}

The neutralizing activity of surface washes of strain BS4 (agar) and of supernatants and deposits after centrifuging the washes at $20000 \mathrm{~g}$. The results in Table 1 show that the surface washes of strain BS4 (agar) neutralized the ability of the antiserum to promote intracellular killing and that centrifugation at $20000 \mathrm{~g}$ left more activity in the supernatant than was found in the deposit. In all of the nine additional tests conducted on separate batches of materials, the surface washes were active and the supernatants from them were more active than the deposits. In several preliminary comparisons of surface washes of BS4 (agar) and sonicates prepared by the method described by Veale et al. (1978), the surface washes and their $20000 \mathrm{~g}$ supernatants were more active than the sonicates and their $20000 \mathrm{~g}$ supernatants.

The $20000 \mathrm{~g}$ supernatant from the surface wash of BS4 (agar) contained pili and several of the antigens that have been described previously (Parsons et al., 1979).

Lack of neutralizing activity in the $20000 \mathrm{~g}$ supernatants of surface washes of strain $B S S H$. Preliminary tests were done to confirm that strain BSSH was more susceptible to 
Table 1. Effect on intracellular killing of strain BS4 (agar) by human phagocytes of antisera against whole gonococci adsorbed with whole surface washes of BS4 (agar) and their fractions

The results shown are representative of 12 experiments, each with different batches of material.

Expt and phagocyte donor

1 (CWP)

2 (MC)

3 (PVP)

\begin{abstract}
Antiserum treatment
\end{abstract}

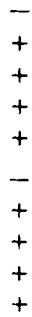

$-$
Antiserum adsorbed with $\uparrow$ :

-
-
Surface wash (N1)
$20000 \mathrm{~g}$ supernatant
$20000 \mathrm{~g}$ deposit

-
-
Surface wash (N2)
$20000 \mathrm{~g}$ supernatant

$20000 \mathrm{~g}$ deposit

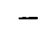

Surface wash (N3) $20000 \mathrm{~g}$ supernatant $20000 \mathrm{~g}$ deposit
Viable gonococci in phagocyte deposit (\% of total microscopic count) $\ddagger$

$25 \cdot 7$

$5 \cdot 1$

17.0

$18 \cdot 1$

$15 \cdot 3$

9.2

$<0.2$

11.7

7.9

7.1

5.8

2.4

9.1

$5 \cdot 5$

$4 \cdot 3$

* +, Pretreatment of gonococci with antiserum against BSDH or BS4 (agar) as described in Methods; - , no pretreatment.

+ Adsorption as described in Methods. N1, N2 and N3 are the batch numbers of the surface washes.

‡ For the phagocytosis tests, suspensions of human phagocytes $\left(10^{6}\right.$; about $80 \%$ PMN phagocytes $)$ were mixed with suspensions of strain BS4 (agar) $\left(10^{6} ;>60 \%\right.$ viable) in Leighton tubes and, after incubation for $1 \mathrm{~h}$ at $37^{\circ} \mathrm{C}$, viable and visual counts of gonococci and counts of total numbers of phagocytes were made as described in Methods.

Table 2. Effect on intracellular killing of strain BS4 (agar) by human phagocytes of antiserum against BS4 (agar) adsorbed with the surface washes from strains BS4 (agar) and BSSH and their $20000 \mathrm{~g}$ supernatants

The results shown are representative of 13 experiments with different batches of surface washes or their $20000 \mathrm{~g}$ supernatants.

\begin{tabular}{|c|c|c|c|}
\hline $\begin{array}{c}\text { Expt and } \\
\text { phagocyte donor }\end{array}$ & $\begin{array}{l}\text { Antiserum } \\
\text { treatment* }\end{array}$ & Antiserum adsorbed with $\dagger$ : & $\begin{array}{r}\text { Viable gonoc } \\
\text { phagocyte } d \\
\text { (\% of total microsc }\end{array}$ \\
\hline $1(\mathrm{MK})$ & $\begin{array}{l}- \\
+ \\
+ \\
+\end{array}$ & $\begin{array}{l}- \\
- \\
\text { Surface wash from BS4 (agar) } \\
\text { Surface wash from BSSH }\end{array}$ & $\begin{array}{r}39 \cdot 6 \\
2 \cdot 2 \\
19 \cdot 1 \\
7 \cdot 4\end{array}$ \\
\hline 2 (DR) & $\begin{array}{l}- \\
+ \\
+ \\
+\end{array}$ & $\begin{array}{l}- \\
\text { Surface wash from BS4 (agar) } \\
\text { Surface wash from BSSH }\end{array}$ & $\begin{array}{r}26.9 \\
0.8 \\
8 \cdot 5 \\
0.8\end{array}$ \\
\hline 3 (DP) & $\begin{array}{l}- \\
+ \\
+ \\
+\end{array}$ & $\begin{array}{c}- \\
- \\
20000 \mathrm{~g} \text { supernatant from BS4 (agar) } \\
20000 \mathrm{~g} \text { supernatant from BSSH }\end{array}$ & $\begin{array}{r}6 \cdot 2 \\
2 \cdot 6 \\
12 \cdot 2 \\
3 \cdot 9\end{array}$ \\
\hline $4(\mathrm{HL})$ & $\begin{array}{l}- \\
+ \\
+ \\
+\end{array}$ & $\begin{array}{c}- \\
- \\
20000 \mathrm{~g} \text { supernatant from BS4 (agar) } \\
20000 \mathrm{~g} \text { supernatant from BSSH }\end{array}$ & $\begin{array}{r}16 \cdot 3 \\
3 \cdot 6 \\
12 \cdot 0 \\
7 \cdot 9\end{array}$ \\
\hline
\end{tabular}

* +, Pretreatment with antiserum against BS4 (agar) as described in Methods; -, no pretreatment.

+ Adsorption as described in Methods.

$\ddagger$ As for Table 1 . 
Table 3. Effect on intracellular killing of strain BS4 (agar) by human phagocytes of antiserum against whole gonococci adsorbed with pili prepared from BS4 (agar)

The results shown are representative of nine experiments, each with different preparations of pili. The pili were suspended at a concentration equivalent to 25 times the original surface wash from $1 \times 10^{11}$ organisms $\mathrm{ml}^{-1}$.

\begin{tabular}{|c|c|c|c|}
\hline $\begin{array}{c}\text { Expt and } \\
\text { phagocyte donor }\end{array}$ & $\begin{array}{l}\text { Antiserum } \\
\text { treatment* }\end{array}$ & $\begin{array}{c}\text { Antiserum } \\
\text { adsorbed witht: }\end{array}$ & $\begin{array}{r}\text { Viable gonococci in } \\
\text { phagocyte deposit } \\
\text { (\% of total microscopic co }\end{array}$ \\
\hline 1 (CWP) & $\begin{array}{l}- \\
+ \\
+ \\
+ \\
+\end{array}$ & $\begin{array}{l}\qquad- \\
\qquad- \\
\text { Pili suspension (N1) undiluted } \\
\text { Pili suspension (N1) } 1 / 5 \\
\text { Pili suspension (N1) } 1 / 10\end{array}$ & $\begin{array}{r}10.8 \\
<0.2 \\
6.1 \\
0.3 \\
<0.2\end{array}$ \\
\hline $2(\mathrm{NJP})$ & $\begin{array}{l}- \\
+ \\
+ \\
+\end{array}$ & $\begin{array}{l}- \\
- \\
\text { Pili suspension (N2) undiluted } \\
\text { Pili suspension (N2) } 1 / 10\end{array}$ & $\begin{array}{r}12.5 \\
1.7 \\
1.5 \\
<0.2\end{array}$ \\
\hline $3(\mathrm{SGC})$ & $\begin{array}{l}- \\
+ \\
+ \\
+ \\
+\end{array}$ & $\begin{array}{l}\qquad- \\
\text { Pili suspension (N3) undiluted } \\
\text { Pili suspension (N3) } 1 / 2 \\
\text { Pili suspension (N3) } 1 / 10\end{array}$ & $\begin{array}{l}5 \cdot 6 \\
0 \cdot 5 \\
2 \cdot 7 \\
1 \cdot 3 \\
0 \cdot 5\end{array}$ \\
\hline $4(\mathrm{SGC})$ & $\begin{array}{l}- \\
+ \\
+ \\
+ \\
+\end{array}$ & $\begin{array}{l}\qquad- \\
\qquad- \\
\text { Pili suspension (N4) undiluted } \\
\text { Pili suspension (N4) } 1 / 2 \\
\text { Pili suspension (N4) } 1 / 10\end{array}$ & $\begin{array}{l}6 \cdot 5 \\
0 \cdot 1 \\
3 \cdot 2 \\
4 \cdot 5 \\
0 \cdot 4\end{array}$ \\
\hline
\end{tabular}

Table 4. Effect on intracellular killing of strain BS4 (agar) by human phagocytes of antiserum against pili (antigen $a$ )

The results shown are representative of six tests on antisera $R 1$ and $R 2$.

\begin{tabular}{|c|c|c|}
\hline $\begin{array}{c}\text { Expt and } \\
\text { phagocyte donor }\end{array}$ & $\begin{array}{c}\text { Treatment with } \\
\text { antiserum* against: }\end{array}$ & $\begin{array}{c}\text { Viable gonococci in } \\
\text { phagocyte deposits } \\
(\% \text { of total microscopic count }) \ddagger\end{array}$ \\
\hline $\mathrm{I}(\mathrm{MH})$ & $\begin{array}{l}\text { BS4 (agar) } \\
\text { Pili (R 1) } \\
\text { Pili (R2) }\end{array}$ & $\begin{array}{r}8 \cdot 7 \\
<0.2 \\
4.9 \\
2.4\end{array}$ \\
\hline $2(\mathrm{MK})$ & $\begin{array}{l}\text { BSDH } \\
\text { Pili (R1) } \\
\text { Pili (R1) adsorbed with BS4R }+\end{array}$ & $\begin{array}{r}24 \cdot 0 \\
0 \cdot 2 \\
16 \cdot 0 \\
24 \cdot 1\end{array}$ \\
\hline $3(\mathrm{HL})$ & $\begin{array}{l}\text { BS4 (agar) } \\
\text { Pili (R2) } \\
\text { Pili (R2) adsorbed with BS4R }+\end{array}$ & $\begin{array}{r}16 \cdot 5 \\
2 \cdot 5 \\
12 \cdot 5 \\
13 \cdot 6\end{array}$ \\
\hline & $\begin{array}{l}\text { atment with antisera was as } \mathrm{d} \\
\text { described by Parsons et al. ( } 1 \\
\text { for Table } 1 \text {. }\end{array}$ & Methods. \\
\hline
\end{tabular}

killing by human phagocytes than strain BS4 (agar), as had been indicated by previous comparisons with the DH strains BS3 (agar) and BS5 (Penn et al., 1977); in three comparisons. the viable gonococci in the phagocyte deposit after $1 \mathrm{~h}$ at $37^{\circ} \mathrm{C}$ were $9.5 \%$, 
Table 5. Effect on intracellular killing of strain BS4 (agar) by human phagocytes of antiserum against outer membrane vesicles (OMV)

The results shown are representative of 13 tests with the antisera R3 and R4.

\begin{tabular}{|c|c|c|}
\hline $\begin{array}{c}\text { Expt and } \\
\text { phagocyte donor }\end{array}$ & $\begin{array}{c}\text { Treatment with } \\
\text { antiserum* against: }\end{array}$ & $\begin{array}{c}\text { Viable gonococci in } \\
\text { phagocyte deposits } \\
\text { (\% of total microscopic count }) \dagger\end{array}$ \\
\hline 1 (PM) & $\begin{array}{l}\text { BSDH } \\
\text { OMV (R3) }\end{array}$ & $\begin{array}{r}8.7 \\
<0.2 \\
<0.2\end{array}$ \\
\hline $2(\mathrm{AK})$ & $\begin{array}{l}\text { BSDH } \\
\text { OMV (R4) }\end{array}$ & $\begin{array}{r}5.1 \\
<0.2 \\
0.7\end{array}$ \\
\hline 3 (PM) & $\begin{array}{l}\text { - } \\
\text { BSDH } \\
\text { OMV (R3) undiluted } \\
\text { OMV (R3) } 1 / 5 \\
\text { OMV (R3) } 1 / 25\end{array}$ & $\begin{array}{l}4 \cdot 7 \\
0 \cdot 4 \\
0 \cdot 6 \\
0 \cdot 2 \\
1 \cdot 3\end{array}$ \\
\hline
\end{tabular}

Table 6. Effect on intracellular killing of strain BS4 (agar) by human phagocytes of antiserum against BS4 (agar) adsorbed with $20000 \mathrm{~g}$ supernatants of surface washes from $B S 4$ (agar) treated with WGA to remove outer membrane vesicles

The results shown are representative of eight experiments.

\begin{tabular}{|c|c|c|c|}
\hline $\begin{array}{c}\text { Expt and } \\
\text { phagocyte donor }\end{array}$ & $\begin{array}{l}\text { Antiserum } \\
\text { treatment }\end{array}$ & Antiserum adsorbed with $\dagger$ : & $\begin{array}{c}\text { Viable gonococci in } \\
\text { phagocyte deposits } \\
\text { (\% of total microscopic count) } \ddagger\end{array}$ \\
\hline $1(\mathrm{PM})$ & $\begin{array}{l}- \\
+ \\
+ \\
+ \\
+\end{array}$ & \begin{tabular}{l}
\multicolumn{1}{c}{-} \\
Supernatant untreated \\
Supernatant treated with WGA \\
WGA (control)§
\end{tabular} & $\begin{array}{r}10 \cdot 6 \\
1.4 \\
10.9 \\
1.7 \\
\text { ND }\end{array}$ \\
\hline 2 (CWP) & $\begin{array}{l}- \\
+ \\
+ \\
+ \\
+\end{array}$ & \begin{tabular}{l}
\multicolumn{1}{c}{-} \\
Supernatant untreated \\
Supernatant treated with WGA \\
WGA (control)§
\end{tabular} & $\begin{array}{r}6.2 \\
<0.2 \\
4.4 \\
<0.2 \\
<0.2\end{array}$ \\
\hline $3(\mathrm{HL})$ & $\begin{array}{l}- \\
+ \\
+ \\
+ \\
+\end{array}$ & \begin{tabular}{l}
$\qquad-$ \\
\multicolumn{1}{c}{-} \\
Supernatant untreated \\
Supernatant treated with WGA \\
WGA (control)§
\end{tabular} & $\begin{array}{r}11 \cdot 6 \\
0.2 \\
4 \cdot 2 \\
0.3 \\
0 \cdot 3\end{array}$ \\
\hline \multicolumn{4}{|c|}{$\begin{array}{l}\text { ND, Not done. } \\
\text { * As for Table } 1 . \\
\dagger \text { Adsorption as described in Methods. } \\
\ddagger \text { As for Table } 1 \text {. } \\
\S \text { WGA control represents antiserum mixed with WGA. }\end{array}$} \\
\hline
\end{tabular}

$8.3 \%$ and $9.0 \%$ of the total microscopic counts for BS4 (agar) and $0.3 \%, 2 \cdot 8 \%$ and $1.7 \%$, respectively, for BSSH.

The results in Table 2 show that, in contrast to the surface wash of BS4 (agar), and its $20000 \mathrm{~g}$ supernatant, the corresponding materials from BSSH (Penn et al., 1977) showed little neutralizing activity.

Lack of significant neutralizing activity in suspensions of pili prepared from the surface wash of strain BS4 (agar). Three of four preparations of pili had some aggressin activity 
when tested at a concentration equivalent to 25 times that of the surface wash (Table 3 ). However, none of them was active when diluted $1 / 10$ and only one showed significant activity at intermediate concentrations. In the five additional tests, the different preparations of pili were inactive at $1 / 10$ dilution while showing some activity when undiluted.

Lack of significant ability of antisera against pili to promote the intracellular killing of strain BS4 (agar). In contrast to antisera against whole organisms, two antisera directed against pili had little ability to inhibit the intracellular survival of BS4 (agar) (Table 4). Traces of antibodies to surface antigens of BS4 (agar) other than pili were probably responsible for the small activity of the antisera in phagocytosis tests, as indicated by the reduction of this small activity that was observed (Table 4) when the antisera were adsorbed with strain BS4R which lacked pilus antigen $a$ but possessed other surface antigens of BS4 (Parsons et al., 1979; Penn et al., 1980).

Promotion of intracellular killing of strain BS4 (agar) by antisera raised against outer membrane vesicles. Two antisera directed against outer membrane vesicles of strain BS4 (agar) were as active as an antiserum raised against whole organisms in promoting the intracellular killing of strain BS4 (agar) (Table 5).

Removal of the neutralizing activity of $20000 \mathrm{~g}$ supernatants of surface washes of strain BS4 (agar) by treatment with WGA. The evidence from Table 5 that the determinant promoting intracellular survival resided in the outer membrane prompted attempts to remove this complex from the $20000 \mathrm{~g}$ supernatants of surface washes by precipitation with WGA. This also removed the neutralizing activity (Table 6).

\section{DISCUSSION}

There is considerable interest in the biochemical nature of the surface components of gonococci, especially those of the outer membrane complex (Heckels, 1977; Swanson, 1978; Lambden \& Heckels, 1979). Also, there have been attempts to relate these components to virulence by comparing their presence or absence in strains of differing biological activity, for example, in serum resistance (Lambden \& Heckels, 1979). While such work correlates biochemical constituents with virulence attributes, it does not prove a causative role (Sparling, 1979: Smith, 1980). There have been few attempts to isolate putative virulence determinants and to prove they are active in relevant biological tests, because the latter are often difficult to conduct. This applies to most areas of gonococcal pathogenicity and certainly to the determinants of resistance to killing by phagocytes.

The approach used in this paper depends on the hypothesis that when prior treatment with homologous antisera promotes the intracellular killing of otherwise resistant gonococci, the determinants of intracellular survival have been neutralized by the antiserum (Veale et al., 1978). This is not necessarily so, for antiserum may activate or enhance alternative killing mechanisms rather than block the determinant directly. It is, however, a reasonable hypothesis, since the action of antiserum was neutralized more effectively by adsorption with a strain of high natural resistance to intracellular killing than with a strain of low resistance (Veale et al., 1978). This point has been underlined here by the greater ability of the surface wash and its fractions from the resistant BS4 (agar) strain compared with those from the susceptible BSSH organisms to neutralize the ability of antisera to promote intracellular killing (Table 2).

The association of pilation with resistance to phagocyte killing was noted in the Introduction, but on the following grounds it appears that the putative determinant is not pili but resides in the outer membrane of resistant gonococci. First, surface washes of the resistant pilated strain BS4 (agar) neutralized the ability of antisera against whole organisms to promote killing (Table 1). These surface washes contained pili (antigen $a$; Penn et al., 1980), 
and outer membrane vesicles (antigen $c$; Perera et al., 1980). At first it appeared that pili might be responsible for resistance. Not only did the phagocyte-susceptible BSSH strain lack pili (Penn et al., 1977), but on centrifuging the surface wash of BS4 (agar) at $20000 \mathrm{~g}$ for $30 \mathrm{~min}$, which would have sedimented some outer membrane complex (Johnston, 1978), the supernatant was always more active than the deposit. However, many preparations of pili purified from the surface washes of BS4 (agar) had only a very low neutralizing effect on antisera against whole organisms (Table 3 ). This activity could probably be explained by the presence of small amounts of other antigens, which were detected in the concentrated suspensions of pili. Supporting the non-involvement of pili in resistance to killing by phagocytes was the fact that antisera against the pilus antigen $a$ had much less effect on intracellular killing of gonococci than antisera against whole organisms, although twodimensional immunoelectrophoresis showed that the different antisera had similar contents of antibodies to the pilus antigen $a$. The low activity of the anti-pili sera can probably be attributed to traces of other antibodies that were detected in two-dimensional immunoelectrophoresis, since this small activity and the traces of other antibodies were removed by adsorption of the antisera with strain BS4R.

Recently, we reported the specific interaction of outer membrane vesicles - antigen $c$ of Parsons et al. (1979) - with WGA (Perera et al., 1980). The possibility that the determinant of intracellular survival was part of the outer membrane complex of strain BS4 (agar) was suggested by the strong promotion of intracellular killing by antisera prepared against aggregates of WGA and outer membrane complex (Table 5). This possibility was strengthened by the removal of the neutralizing activity of the surface wash supernatant by precipitation with WGA (Table 6) and is supported by the activity of the $20000 \mathrm{~g}$ deposit (Table 1) which undoubtedly contained some larger outer membrane complexes. Obviously, future work will concentrate on the constituents of the outer membrane of BS4 (agar) in contrast to those of the relatively inactive membrane from BSSH.

\section{REFERENCES}

Bonting, S. L. \& Jones, M. (1957). Determination of microgram quantities of deoxyribonucleic acid and protein in tissues grown in vitro. Archives of Biochemistry and Biophysics 66, 340-353.

Casey, S. G., Veale, D. R. \& Smith, H. (1979). Demonstration of intracellular growth of gonococci in human phagocytes using spectinomycin to kill extracellular organisms. Journal of General Microbiology 113, 395-398.

Casey, S. G., Veale, D. R. \& Smith, H. (1980). Intracellular survival of Neisseria gonorrhoeae in human urethral exudate. FEMS Microbiology Letters 8, 97-100.

FarzadegAN, H. \& Roth, I. L. (1975). Scanning electron-microscopy and freeze-etching of gonorrhoeal urethral exudate. British Journal of Venereal Disease 51, 83-91.

HECkels, J. E. (1977). The surface properties of Neisseria gonorrhoeae, isolation of the major components of the outer membrane. Journal of General Microbiology 99, 333-341.

JoHNSTON, K. H. (1978). In Immunobiology of Neisseria gonorrhoeae, pp. 121-129. Edited by G. F. Brooks, E. C. Gotschlich, K. K. Holmes, W. D. Sawyer \& F. E. Young. Washington, D.C.: American Society for Microbiology.

LAMBden, P. R. \& Heckels, J. E. (1979). The influence of outer-membrane protein composition on the colonial morphology of Neisseria gonorrhoeae. FEMS Microbiology Letters 5, 263-265.
Novotny, P., Short, J. A. \& WALker, P. D. (1975). An electron-microscopic study of naturally occurring and cultured cells of Neisseria gonorrhoeae. Journal of Medical Microbiology 8, 413-427.

Ovchinnikov, N. M. \& DelektorskiJ, V. V. (1977). Phagocytosis in urethral discharge from patients with gonorrhoea. In Gonorrhoea: Epidemiology and Pathogenesis, pp. 157-183. Edited by J. A. Skinner, P. D. Walker \& H. Smith. London: Academic Press.

Parsons, N. J., Penn, C. W., Veale, D. R. \& Smith, H. (1979). More than one antigen contributes to the immunogenicity of Neisseria gonorrhoeae in the guinea-pig subcutaneous chamber model. Journal of General Microbiology 113, 97-104.

Parsons, N. J., Penn, C. W., Veale, D. R. \& Smith, H. (1980). The complexity of immunogenicity of Neisseria gonorrhoeae in the guinea pig subcutaneous chamber model. Journal of General Microbiology 118, 523-527.

Penn, C. W., Sen, D., Veale, D. R., Witt, K.. Parsons, N. J. \& SMITh, H. (1976). Morphological, biological and antigenic properties of Neisseria gonorrhoeae adapted to growth in guineapig subcutaneous chambers. Journal of General Microbiology 97, 35-43.

PenN, C. W., Veale, D. R. \& Smith, H. (1977). Selection from gonococci grown in vitro of a colony type with some virulence properties of organisms adapted in vivo. Journal of General Microbiology $100,147-158$. 
Penn, C. W., Parsons, N. J., Veale, D. R. \& Smith, H. (1978). Correlation with different immunotypes of gonococcal antigens associated with growth in vivo. Journal of General Microbiology 105, 153157.

Penn, C. W., Parsons, N. J., Veale, D. R. \& Smith, H. (1980). Antigenic heterogeneity associated with pilus aggregation and autoagglutinability in Neisseria gonorrhoeae. Journal of General Microbiology 121, 195-202.

Perera, V. Y.. Penn, C. W. \& Smith, H. (1980). The use of specific antiserum induced by lectin-antigen complexes to investigate the outer membrane antigens of Neisseria gonorrhoeae. Journal of Immunological Methods 37, 175-184.

Robertson, J. N., VINCEnT, P. \& WARD, M. E. (1977). The preparation and properties of gonococcal pili. Journal of General Microbiology 102, 169-177.

SmITH. H. (1980). Introduction. In The Molecular Basis of Microbial Pathogenicity, Dahlem Konferenzen 1980, pp. 11-16. Edited by H. Smith, J. J. Skehel \& M. J. Turner. Weinheim: Verlag Chemie.

SPARLING, P. F. (1979). Use of microbial genetics in the study of pathogenicity; differentiation between correlation and causation. In Microbiology - 1979, pp. 249-253. Edited by D. Schlessinger. Washington, D.C.: American Society for Microbiology.

Swanson, J. (1978). Cell wall outer membrane variants of Neisseria gonorrhoeae. In Immunobiology of Neisseria gonorrhoeae, pp. 130-137. Edited by G. F. Brooks, E. C. Gotschlich, K. K. Holmes, W. D. Sawyer \& F. E. Young. Washington, D.C.: American Society for Microbiology.

Veale. D. R.. Smith. H.. Witt, K. \& Marshall.
R. B. (1975). Differential ability of colonial types of Neisseria gonorrhoeae to produce infection and an inflammatory response in subcutaneous perforated plastic chambers in guinea-pigs and rabbits. Journal of Medical Microbiology 8, 325-335.

Veale, D. R., Finch, H., Smith, H. \& Witt, K. (1976). Penetration of penicillin into human phagocytes containing Neisseria gonorrhoeae: intracellular survival and growth at optimum concentrations of antibiotic. Journal of General Microbiology 95, 353-363.

Veale, D. R., Penn, C. W., Sutton, S. \& Smith, H. (1978). The effects of specific antiserum on the resistance of Neisseria gonorrhoeae to intracellular killing by phagocytes of human blood. Journal of General Microbiology 106, 129-136.

Veale, D. R., Goldner, M., Penn, C. W., Ward, J. \& SMrTh, H. (1979). The intracellular survival and growth of gonococci in human phagocytes. Journal of General Microbiology 113, 383-393.

WARD, M. E., GlynN, A. A. \& WaTt, P. J. (1972). The fate of gonococci in polymorphonuclear leukocytes: an electron-microscopic study of the natural disease. British Journal of Experimental Pathology 53, 289-294.

Witt, K., Veale, D. R., Finch, H., Penn, C. W., Sen, D. \& SMITH, H. (1976a). Resistance of Neisseria gonorrhoeae grown in vivo to ingestion and digestion by phagocytes of human buffy coat. Journal of General Microbiology 96, 341-350.

WITT, K., Veale, D. R. \& Smith, H. (1976 b). Resistance to ingestion and digestion of Neisseria gonorrhoeae by phagocytes of human buffy coat. Journal of Medical Microbiology 9, 1-12. 